\title{
O processo de ensino e aprendizagem para criança autista nos anos iniciais do ensino fundamental
}

\section{The teaching and learning process for autistic children in the early years of elementary school}

DOI: $10.54019 / \operatorname{sesv3n1-019}$

Recebimento dos originais: 15/01/2022

Aceitação para publicação: 10/02/2022

\author{
Sandra Horstmann Patrício \\ Pós-graduada em Alfabetização e Letramento pelo ICEET, e em Neuropedagogia \\ na educação pelo Instituto Rhema. \\ E-mail: shorstmannpatricio@yahoo.com.br
}

\section{RESUMO}

O autismo é uma síndrome do desenvolvimento que se manifesta normalmente em crianças antes dos dois anos de idade, descrito como autismo. O transtorno autista (ou autismo infantil) faz parte de um grupo de transtornos do neurodesenvolvimento denominados Transtornos Globais do Desenvolvimento (TGDs). Segundo os critérios do DSM-IV-TR, para que a criança seja diagnosticada com transtorno autista, ela deve apresentar pelo menos seis da lista de doze sintomas apresentados na Tabela 1, sendo pelo menos um na área de comunicação, pelo menos um na área de comportamentos restritos, repetitivos e estereotipados e pelo menos dois dos sintomas devem ser na área de interação social.Abordaremos também como se dá o processo de ensino e aprendizagem de cada ser humano, ou seja, o modo de aprendizagem de cada pessoa que trás consigo uma bagagem de conhecimentos, mas como cada um aprende, retém a aprendizagem, sabendo que cada indivíduo sofre, durante toda a sua vida, a influência dos agentes externos de natureza física e social,ou será, O processo para uma aprendizagem eficaz depende de inúmeros fatores, dentre os quais, os mais relevantes são: o talento do professor, o tipo intelectual do aluno, as oportunidades oferecidas pelo ambiente imediato da escola, a perspectivas futuras de vida do aluno, entre outros.E como sabemos a importância dessa síndrome e a importância da aprendizagem em nossa vida, iremos também refletir sobre como se dá esse processo de ensino aprendizagem e como crianças portadoras dessa síndrome conseguem aprender. O objetivo deste artigo é conhecer um pouco mais sobre esse tema, que muitos ainda desconhecem, atualmente a mídia vem relatando sobre essa síndrome, porém ainda não é o suficiente devido a déficit de informações o artigo trás também, as formas de lidar com portadores, no ambiente escolar, os níveis do autismo e a interação social. Dessa forma, possibilitar aos pais e educadores uma visão mais ampla e um conhecimento a mais nesta área.

Palavras-chave: autismo, processo de ensino e aprendizagem 


\section{ABSTRACT}

Autism is a developmental syndrome that usually manifests itself in children before the age of two, described as autism. Autistic disorder (or childhood autism) is part of a group of neurodevelopmental disorders called Global Developmental Disorders (DTs). According to the Criteria of the DSM-IV-TR, for the child to be diagnosed with autistic disorder, he/she must present at least six of the list of twelve symptoms presented in Table 1, with at least one in the communication area, at least one in the area of restricted, repetitive and stereotyped behaviors and at least two of the symptoms should be in the area of social interaction. We will also discuss how the teaching and learning process of each human being takes place, that is, the way in which theprediction of each person who carries with hima baggage of knowledge, but as each one learns, retains learning, knowing that each individual suffers, throughout his life, the influence of external agents of physical and social nature, or will be, The process for effective learning depends on numerous factors, among which, the most relevant are: the talent of the teacher, the intellectual type of the student, the opportunities offered by the immediate environment of the school, the future prospects of the student's life, among others. And as we know the importance of this syndrome and the importance of learning in our lives, we will also reflect on how this learning teaching process takes place and how children with this syndrome can learn. The aim of this article is to know a little more about this topic, which many still do not know, currently the media has been reporting on this syndrome, but it is still not enough due to information deficit the article behind also, the ways to deal with carriers, in the school environment, autism levels and social interaction. Thus, to enable parents and educators a broader vision and an even more knowledge in this area.

Keywords: autism, teaching and learning process

\section{INTRODUÇÃO}

Neste artigo abordaremos uma síndrome do desenvolvimento, que se manifesta normalmente em crianças antes dos dois anos de idade, descrito como autismo. O transtorno autista faz parte de um grupo de transtornos do neurodesenvolvimento, denominados Transtornos Globais do Desenvolvimento (TGDs). É um dos distúrbios mais comuns na infância e uma das principais causas de procura de atendimento em unidades ambulatoriais de saúde mental e seus sintomas podem ocorrer com crianças muito novas. Os sinais iniciam-se antes dos três anos de idade à exceção da Síndrome de Rett.

Segundo os critérios do DSM-IV-TR, para que a criança seja diagnosticada com transtorno autista, ela deve apresentar pelo menos seis da lista de doze sintomas apresentados na Tabela 1, sendo que pelo menos dois dos sintomas devem ser na área de interação social, pelo menos um na área de comunicação, 
e pelo menos um na área de comportamentos restritos, repetitivos e estereotipados.

Os casos de autismo têm crescido em todo mundo de forma significativa nas últimas décadas e com ele a déficit de informações e conhecimentos a respeito. E para profissionais, educadores e pais é de extrema importância 0 conhecimento desse transtorno. Devido a esse déficit e carência de informação e a inserção de poucos trabalhos abordando o assunto, fez-se necessário a abordagem deste artigo para contribuir com meus colegas de profissão, e toda população a fim de conhecer um pouco mais sobre esse assunto que está tão inserido em nosso cotidiano.

Neste artigo conheceremos um pouco mais sobre o assunto, a história, as causas, listar meios que facilitarão o ensino e aprendizagens desses alunos com autismo, maneiras de lidar, entre outros.

\section{AUTISMO}

Segundo (ORRU,2012, p.17). O termo "autismo é de origem grega, quer dizer "autós" ou "de si mesmo", foi incorporado na psiquiatria, para designar condutas, atitudes humanas que centralizam em si mesmo, ou seja, voltados para o próprio indivíduo.

De acordo com a CID -11 Internation Statistical Classification ft Diseasesabd Related Health Problems), em 20130 autismo passou por várias modificações sendo englobado no grupo do transtorno espectro Austista, de acordo como Manual Diagnóstico e estatístico de Transtornos mentais, qualificado no DSM-V.

Em 1908 foi criado o termo autismo pelo psiquiatra suíço Eugen Bleuler descrevendo assim uma fuga para um mundo interior observado em pacientes esquizofrênicos.

Segundo Kanner(1), em 1943, O Autismo Infantil foi definido, sendo inicialmente denominado Distúrbio Autístico do Contato Afetivo, como uma condição com características comportamentais bastante específicas, tais como: perturbações das relações afetivas com o meio, solidão autística extrema, inabilidade no uso da linguagem para comunicação, presença de boas potencialidades cognitivas, aspecto físico aparentemente, normal, 
comportamentos ritualísticos, início precoce e incidência predominante no sexo masculino.

Segundo Asperger (2) em 1944 propôs em seu estudo a definição de um distúrbio que ele denominou Psicopatia Autística, que se manifesta por transtorno severo na interação social, uso pedante da fala, desajeitamento motor e incidência apenas no sexo masculino. O mesmo utilizou a descrição de alguns casos clínicos, caracterizando a história familiar, aspectos físicos e comportamentais, desempenho nos testes de inteligência, além de enfatizar a preocupação com a abordagem educacional destes indivíduos. Os trabalhos realizados pelos os dois autores tiveram impacto na literatura mundial; no entanto, em momentos diferentes. As descrições de Kanner (1) foram rapidamente absorvidas pela comunidade científica. A abordagem etiológica do Autismo Infantil, proposta pelo autor, salientava a existência de uma distorção do modelo familiar, que ocasionaria alterações no desenvolvimento psicoafetivo da criança, decorrente do caráter altamente intelectual dos pais destas crianças.

Apesar desta proposição, o autor não deixou de assinalar que algum fator biológico, existente na criança, poderia estar envolvido, uma vez que as alterações comportamentais eram verificadas precocemente, o que dificultaria a aceitação puramente relacional. Esses referenciais para a hipótese etiológica foram, de certo modo, precursores de duas abordagens teóricas distintas para o estudo do Autismo Infantil, ainda hoje motivo de controvérsias.

A teoria afetiva propõe uma etiologia puramente relacional e, embora faça a distinção entre a síndrome descrita por Kanner e sua abordagem clínica, considera que o autismo é mais um sintoma do quadro clínico de Psicose Infantil e menos uma entidade nosológica em si (3-5). Ainda hoje, a teoria afetiva é preconizada e difundida na literatura psicanalítica, embora alguns autores tenham revisto seus referenciais teóricos, a respeito da etiologia, como é o caso de uma das precursoras (5) desta teoria, que revisou os próprios conceitos teóricos acerca da definição de autismo. Segundo a autora, à luz das descobertas produzidas pela observação dos comportamentos dos bebês, não seria mais possível postular uma fase de autismo primário infantil, uma vez que, são observadas, desde muito cedo, reações do neonato ao meio. Sugeriu que o autismo deveria ser compreendido, apenas, como sendo uma condição patológica. Além disso, 
questionou a presença de possíveis alterações orgânicas, na criança, não detectáveis em exames disponíveis naquele momento.

O autismo vem sendo estudado por pesquisadores e médicos há mais de 100 anos. Sabemos então que as causas do TEA não são totalmente conhecidas, e a pesquisa científica sempre concentrou esforços no estudo da predisposição genética. No entanto, já há evidências de que as causas hereditárias explicariam apenas metade do risco de desenvolver TEA. Há fatores ambientais que também impactam o feto, como infecções, estresse, exposição a substâncias tóxicas, complicações durante a gestação e desequilíbrios metabólicos teriam o mesmo peso na possibilidade de aparecimento do distúrbio tóxicas, complicações durante a gravidez e desequilíbrios metabólicos teriam o mesmo peso na possibilidade de aparecimento do distúrbio.

O TEA pode ser notado em bebês de poucos meses, no geral, uma criança com autismo apresenta os seguintes sintomas:

\begin{abstract}
Dificuldade para interagir socialmente, como manter o contato visual, expressão facial, gestos, expressar as próprias emoções e fazer amigos; Dificuldade na comunicação, optando pelo uso repetitivo da linguagem e bloqueios para começar e manter um diálogo; Alterações comportamentais, como manias, apego excessivo a rotinas, ações repetitivas, interesse intenso em coisas específicas, dificuldade de imaginação e sensibilidade sensorial (hiper ou hipo).(APA, 2014, p.54).
\end{abstract}

Justamente por se manifestar por vários distúrbios, o Manual Diagnóstico e Estatístico de Transtornos mentais DSM-5 rotula esses distúrbios como espectro por se manifestarem de diferentes níveis de intensidade.

$\mathrm{Na}$ Alta funcionalidade - Apresenta prejuízos leves, que não impedem que a pessoa estude, trabalhe ou se relacione.

Na Média funcionalidade- Tem menor grau de independência, necessita de auxílio para desempenhar suas funções cotidianas.

Na Baixa funcionalidade - Manifesta um alto grau de dependência, possui dificuldades graves, costuma precisar de apoio ao longo da vida.

O TEA possui também um lado bom, seu diagnóstico pode ser acompanhado de habilidades impressionantes, como grande concentração em uma área por longo período, facilidade em aprender visualmente, muita atenção a detalhes e à exatidão. 
Cada indivíduo vai se desenvolver conforme as suas características, que são bastante particulares.

\section{O QUE É APRENDIZAGEM E COMO ELA ACONTECE NO SER HUMANO}

A forma tradicional de conhecimento presente nas escolas centrava - se na figura do docente, sendo tratado como "detentor do saber". Hoje percebemos mudanças no cenário. Os docentes desafiam os estudantes, mostrando-lhes, várias possibilidades e caminhos a percorrer no quesito aprendizagem. Vamos ver segundo vários pesquisadores a denominação da aprendizagem e como ela acontece no ser humano.

A aprendizagem é um processo de assimilação de determinados conhecimentos e modos de ação física e mental, organizados no processo ensino aprendizagem. Compreendemos que todo ser humano aprende de uma alguma maneira, não necessariamente todos do mesmo jeito. Sendo assim, veremos vários autores falando sobre o a aprendizagem.

Segundo Vygoysky, as fases do desenvolvimento da criança são estudadas por vários autores com abordagens diferentes. Denominou que, no processo de aprendizagem, a interação é constante e acontece por meio do desenvolvimento real, desenvolvimento potencial e zona do desenvolvimento proximal. Que é um conceito que define a distância entre o nível de desenvolvimento real, sendo a capacidade de resolver um problema sem ajuda. Nível de desenvolvimento potencial é a resolução de um problema sob a orientação de um adulto ou em colaboração com outro companheiro (uma criança mais velha). Zona de Desenvolvimento Proximal define aquelas funções que ainda não amadureceram, mas estão partindo para o processo de maturação.

Para Piaget há uma separação da aprendizagem e desenvolvimento, a aprendizagem vem devido à resposta particular, proferindo da experiência, sistemática ou não, enquanto que o desenvolvimento seria uma aprendizagem de fato, sendo este o responsável pelos conhecimentos.

Na teoria piagetiana o desenvolvimento da criança é descrito, basicamente, em quatro estados, considerados como fases de transição. Essas quatro fases são: (1) Sensório-motor (0 - 2 anos), (2) Pré-operatório-operatório (2 - 7,8 anos). (3) Operatório-concreto (8 - 11 anos) e (4) Operatório-formal (8 - 14 anos). 
Para Skinner um sujeito aprende quando produz modificações no ambiente.

Isto significa que algo de novo foi ensinado de maneira adaptativa, passando a ser emitido um novo comportamento pelo indivíduo.

Segundo Wallon (2010 p. 17).

Responsável pelo método heurístico que procura compreender as diversas compreensões das dimensões da compreensão humana, por serem indissociáveis e vinculadas, promovem o desenvolvimento humano. -Destaca- se por explorar aptidões afetivas e atividades motoras, via de regra, desprezadas na analise desse tema, tem importância decisiva no complexo Inter jogo funcional responsável pelo desenvolvimento da criança.(WALLON,2010 p.17).

O autor ressalta que afetividade é essencial na transformação e construção do conhecimento na pessoa.

O desamparo biológico que caracteriza os dois primeiros anos de vida, em razão das precárias condições de maturidade orgânica, determina um longo período de absoluta dependência das crianças dos cuidados de um adulto para poder sobreviver. Isso torna afetividade a força que garante a mobilização do adulto para atender as necessidades. Afirmando que a expressão emocional é fundamentalmente social, pois precede e supera os recursos cognitivos. (WALLON,2010 p. 29).

Detalhando minuciosamente as origens da emotividade, afasta-se de um modelo biologista procura compreender a natureza humana.

Para ele o ser humano é organicamente social. -Isto porque esta nesta força da emotividade humana e em seu caráter contagioso e epidêmico as condições que seja mediada pela cultura interpretada pelo adulto e promotora, a partir de então, do desenvolvimento cognitivo da criança. Significa que o bebê apresenta insatisfação em relação ao choro, que de inicio é sua única forma de relacionar-se. -Esse choro mobiliza a mãe e ela interpreta com seus valores e significados culturais. A relação entre ambos será responsável pela maturação das funções cognitivas da criança. (WALLON,2010 p.45).

A segunda consideração levantada é sobre a ação motora, que vão além da tarefa de executar ações pesadas.

$O$ ato motor do ser humano garante desde o inicio a função da expressão da afetividade -(por meio dos gestos, expressões faciais e agitação corporal). -Essa atividade expressiva é possibilitada pela atividade motora, regula, modula e produz estados emocionais. (WALLON,2010 p. 154). 
A avaliação revela muitas vezes que os pacientes com autismo não têm problemas cognitivos voltados para o campo da inteligência.

[...]demostra que a dificuldade cognitiva que mais aparece nos casos são de ordem afetiva não estando ligada a ideia de trauma emocional, sua dificuldade esta em analisar os estudos mentais de outros denominada metarrepresentação sendo necessária para representações simbólicas e pragmáticas. (BAREN COHEN, 2012, p.113).

Nessa perspectiva, podemos perceber que a educação possibilita a cada aluno um acesso diferenciado às áreas do saber e as suas particularidades. Sendo assim, cada um tem a sua maneira de aprender, seu tempo no espaço e suas especificidades.

\section{PROCESSO DE ENSINO E APRENDIZAGEM PARA CRIANÇA AUTISTA} NOS ANOS INICIAIS DO ENSINO FUNDAMENTAL

O transtorno do Espectro do Autismo (TEA) é uma condição bastante complexa e uma das consequências disso é que cada autista apresenta características diferentes do outro, os sintomas variam de leve a grave, classificados em nível 1,2 e 3, moderado e severo.

O autismo classifica em áreas do desenvolvimento: "habilidades de interação social recíproca, habilidades de comunicação e presença de comportamentos e interesses restritos" (KUBASKI, 2014, p. 15).

Pensando na necessidade de uma escola que acolha todos os alunos, afirma a Lei no 12.764, que institui a "Política Nacional de Proteção dos Direitos da Pessoa com Transtorno do Espectro Autista".Apresentamos a aprendizagem dos alunos com autismo. Segundo Wallon,

\footnotetext{
Wallon nos diz que são três as competências que devem ser trabalhadas, as quais chamou de campos funcionais: a psicomotricidade (movimento), a afetividade (emoções) e a inteligência. Estas três teorias podem ser visualizadas ao longo do ano ao qual a criança se encontra matriculada em diferentes níveis sendo os iniciais menos complexos e os finais mais bem elaborados a partir dos conhecimentos iniciais que passaram por uma maturação no campo da inteligência. Mas mesmo assim encontramos alunos com dificuldades que nem sempre englobam os três campos, mas apenas um, retomando a teoria dos campos funcionais é possível notar que problemas de maturação das funções estão intimamente ligados ao convívio psicossocial do aluno (WALLON, 1979, p.59),
} 
As características do espectro são variadas, se definem por danos persistentes na comunicação e interação social, bem como padrões limitados ou estereotipados. As anormalidades estão presentes em torno dos três anos de idade, que limitam ou prejudicam o funcionamento diário do indivíduo.

Crianças diagnosticadas com Transtorno Espectro Autistas apresentam dificuldades de comunicação que não abrangem apenas os fatos de serem verbais e não verbais, mas, sim, impedimentos para opiniões, expressar seus sentimentos e desejos.

A frustração dos pais é a de que seus filhos não falam, desviam o olhar e brincam sozinhos. É preciso que ocorra, além da fala, a interação, ou seja, a funcionalidade, é preciso que ocorra, além da fala, a interação entre as partes.

Em sala de aula, é necessário que a professora faça um planejamento adequado as especificidades dos alunos com esse transtorno, é preciso fazer um plano de aula flexibilizado, permitindo a facilidade e assegurando que o aluno consiga aprender.

\section{CONSIDERAÇÕES FINAIS}

Os pais se preocupam quando seus filhos, não interagem com outras crianças, e quando demoram para falar. Até descobrir o que seus filhos tem, eles ficam aflitos. Sabemos então, que a informação sobre essa síndrome está se tornando bastante comum para a mídia, e que os pais e profissionais da educação não tem informações e nem formação necessária. Então para que a criança seja diagnosticada com transtorno autista, ela deve apresentar pelo menos seis da lista de doze sintomas apresentados na Tabela 1, sendo que pelo menos dois dos sintomas devem ser na área de interação social, pelo menos um na área de comunicação, e pelo menos um na área de comportamentos restritos, repetitivos e estereotipados.

É importante que o professor saiba que não é detentor do saber, aprende constantemente com seus alunos, precisam ter a consciência que a troca de experiência entre professor e aluno é extremamente importante. Nessa perspectiva a formação dos profissionais da educação na construção de conhecimento para as práticas educacionais que promovem o desenvolvimento sócio cognitivo dos estudantes Espectro Autista são extremamente importantes. 
Os autistas têm direito de estudar em escolas regulares, na Educação Básica no Ensino Profissionalizante, precisando, poderão solicitar um acompanhante especializado, essa descrição, esta instituída no art. 20 Último Parágrafo da Política Nacional de Proteção dos Direitos da Pessoa com Transtorno do Espectro Autista.

O transtorno do Espectro do Autismo (TEA) é uma condição bastante complexa e uma das consequências disso é que cada autista apresenta características diferentes do outro, os sintomas variam de leve a grave, classificados em nível 1,2 e 3, moderado e severo.

Em sala de aula, é necessário que a professora faça um planejamento adequado às especificidades dos alunos com esse transtorno, é preciso fazer um plano de aula flexibilizado, permitindo a facilidade e assegurando que o aluno consiga aprender. 


\section{REFERÊNCIAS}

JUNQUEIRO, Patricia Grandino. WALLON E A PSICOGENÊSE NA EDUCAÇÃO BRASILEIRA. Pg. 31-55. 2010. . Recife: Fundação Joaquim Nabuco, Editora Massangana

KUBASKI, C. A inclusão de alunos com transtorno do espectro do autismo na perspectiva de seus professores: estudo de caso em quatro escolas do município de Santa Maria/RS. Dissertação (Mestrado em Educação) Universidade Federal de Santa Maria, Santa Maria, 2014.

ORRÚ, S. E..Autismo, linguagem e educação: interação social no cotidiano escolar. Rio de Janeiro: Wak, 2012

Piaget J. Cómo se desarollala mente del niño. In: Piaget J. Los años postergados: la primera infancia. Paris: UNICEF; 1975.

Skinner BF. Tecnologia do ensino. São Paulo: Herder; 1972. 